\title{
Gender Representations in Social Media and Formations of Masculinity
}

\author{
Maya Parkins ${ }^{1}$ and John Parkins ${ }^{1}$ \\ ${ }^{1}$ University of Alberta, Edmonton, AB, Canada \\ DOI: https://doi.org/10.47611/jsr.v10i1.1144
}

\begin{abstract}
Social media has become a primary socializer by shaping the identity and perspectives of its users. Gender socialization is the process in which people learn and internalize norms and behaviours associated with their respective gender. Through their own social media platforms, influencers post representations of self that they feel represent themselves in the world. Since these influencers are popular, many adolescents are able to see and process these photos and videos as a part of their own process of identity formation. This study asks the question, how do male influencers demonstrate masculinity through their posts and comments? The literature reviewed for this study offers insight on the formation and representation of masculinity. Key concepts include hegemonic masculinity and defensive heterosexuality which aid in understanding masculinity as it is manifested in our society. The study sample includes ten male instagram influencers. Five photos were taken from their account that demonstrated representation of self and were then evaluated based on six factors. The results of this study show that these influencers are in fact demonstrating specific modes of masculinity through their photos which is consistent with how masculinity is portrayed in society today. However, these photos also demonstrate that some male influencers are shifting away from patriarchal forms of masculinity and are showing more interest in grooming and fashion, therefore highlighting a metrosexual mode of masculinity.
\end{abstract}

\section{Introduction and Research Questions}

Socialization is a term often used by sociologists to describe the process by which people learn and internalize societal norms and behaviours. This process begins in infancy as children learn how to navigate the world around them through actions and attitudes. The strongest socialization a child may experience is through their primary socializers, including immediate family, friends and the education system. However, socialization is a broad topic and has many subcategories including religious socialization, political socialization, occupational socialization, etc. For this study, I focus on gender socialization. Long before a child can write, speak a new language or understand the depth of their religion they attach to the social construct of gender and can fully realise if they are male or female (Stockard, 2006 p.215). The world is built on the premises of gender socialization as we assign different gender roles and responsibilities along with varying value and rewards (Stockard, 2006 p.215).

Masculinity and femininity are two concepts that go hand in hand with the concept of gender. It is widely recognized that masculinity belongs with the male gender and femininity goes with being female. Children are socialized into their respective category based on their sex. Primary socializers, such as parents will dress kids in clothing that demonstrates their gender while at school children learn the divide between their male and female classmates. However, in recent years, social media has also become a primary socialization tool. The role of media in socialization is especially strong for adolescents as they begin to grow apart from their families and seek independence (Kelly, Donohew, 1999 p.1033). Social media is now a part of everyday life for many individuals and is especially popular with young adults - giving social media influencers (a user who has a wide following and established credibility) the opportunity to reach a wide fan base and increase their popularity. 
With young adults being highly impressionable and with an early-life journey toward self-discovery, can social media influencers be a part of gender socialization? This research focuses on masculinity with attention to male Instagram influencers. In this study, I address the following question: how do male influencers demonstrate masculinity through their posts and comments? Before we examine the results of this analysis, I provide a brief review of the published literature on this topic and a summary of my research methods.

\section{Literature Review}

The literature on this topic offers a depth of knowledge as to how masculinity manifests in today's society. A study conducted by Dutro (2002) explores how a group of young boys perform masculinity in relation to their reading practices. It was in this text that I was introduced to the term hegemonic masculinity. Hegemonic masculinity can be described as masculinity by which all other masculinities are measured. This was especially prevalent in Dutro's study as the "less popular" boys were victimized to be seen as lesser because they did not play sports, which in this class, was viewed as primarily masculine behaviour (i.e. hegemonic masculinity.) This study also explored how young boys already have a deep understanding of what it means to be mascline and how it influences their young lives in the classroom and also their interpersonal relationships. Another article by Philarethou and Allen (2001) explains masculinity as essentialists by "[defining] and [distributing] gender roles and identities across traditional masculine and feminine boundaries, elevating masculine identity to a superior status in the social hierarchy" (Philarethou and Allen, 2001, p.302). In this article, it is stated that to be male it "requires one's molding into a masculine role, which presupposes autonomy, competition, and aggressiveness and the suppression of the innate human needs for connectedness, intimacy, and self-disclosure..." (Philarethou, Allen, 2001, p.301). These traits are distinctly human which can add value to the thought that what is masculine is traditionally what is not feminine. Masculinity, however, is also rooted in sexuality as the frame around masculine sexuality has established unrealistically high standards around male sexual performance and satisfaction. The heterosexual sexual script, according to essentialist ideology, focuses heavily on the male with sex begginning with male erection and ending in ejaculation meaning all sexual satisfaction is based on the male, thus paying little to no attention to female sexual experience. Again, according to the essentialist idea, sex for males has become an act of power, dominance and an opportunity to release deep aggressive emotions.

Widely accepted power-fueled expressions of male sexuality tend to covertly lead towards feelings of sexual inadequacy, dissatisfaction and inability. This can be attributed to the majority of men being unable or unwilling to live up to the demanding masculine roles set forth by essentialist sexual scripts. This is when the term masculine deprivation comes into effect as it is the situation characterizing such males who fail to live up to essentialist masculine expectations and as a result become swallowed by a state of male sexual anxiety with clinical and non-clinical consequences (Fracher \& Kimmel, 1992). A study conducted by Anderson (2005), followed a group of male cheerleaders and four selected cheer teams examining the construction of masculinity among college-aged heterosexual male cheerleaders. Anderson's research showed two contrasting forms of normative masculinity being displayed by the male cheerleaders. The first category of performance is labeled orthodox as the men in this group are shown to perform masculinity in a more traditional style as they attempt to maintain the hegemonic form of masculinity and largely devalue women and gay men. The second category is labeled as inclusive as the men in this group willingly embrace the feminized undertones of the sport and value their gay teammates. This category of performance is not based on homophobia and anti-feminism and does not view hegemonic masculinity as desirable.

The emergence of inclusive forms of masculinity can be linked to many factors including the structure of the sport, reduction of cultural, institutional, and organizational homophobia and the resocialization of men into a genderintegrated sport. Additionally, the research showed that male cheerleaders who wanted a public image of heterosexuality must prove and reprove their masculinity. Most men in the orthodox group did so by displays of defensive heterosexuality. Defensive heterosexuality can be characterized by expressive signaling of heterosexuality through a variety of repeated mechanisms. The most common use of this expression between heterosexual male cheerleaders was the constructed story about men lusting after their female teammates. However, men in the inclusive group chose not 
to value what people perceived of them and were less concerned about associating with femininity. The men in this group were "less (or not at all) defensive about their heterosexuality and regularly stated support for homosexuality... conversely, homophobic expression was stigmatized among men in this group" (Anderson, 2005, p.351). The emergence of the two types of normative masculinity displayed by men in feminized terrain suggests that there is variation as to how males view and interpret the masculine ideals in today's society suggested in the article by Philarethou and Allen (2001). In terms of socialization, part of the variation of masculine ideals may be attributed not only to values instilled in a man by family, friends and school but could also be attributed to their social media consumption. In this study presented here, we dig into these concepts, with an attempt to understand the dominant expressions of masculinity as represented by Instagram influencers.

\section{Method}

The sociologist Erving Goffman introduced many new concepts related to individuals and their public image in social contexts. In his book, The Presentation of Self in Everyday Life (1959) Goffman introduced the dramaturgical metaphor in which he explained that people live their life in two seperate states, the front stage and the backstage. Your front stage self is the person you are when you are out about in the world whether it's eating out at a restaurant, at a mall or walking around a park and is also influenced by impression management. Your backstage self is who you are at home or when you are truly by yourself. Goffman looked at how we presented ourselves and how others would view us. His work with print magazines, looking at how genders are portrayed in media has been replicated and reviewed repeatedly as a timeless contribution to sociological literature.

In this study, I look at how the media portrays gender with a focus on males on their own social media platforms. Some of Goffman's criteria for his 1976 study is used in this study as well such as function ranking and family portrayal. Goffman described function ranking as the task that a model does in a photo. In some ways, the task relates to the concept of social standing. However, my behaviour category for men looks at whether men prefer to post photos of themselves engaging in activities or just posing. Likewise, Goffman described family portrayal as who is present and involved in the photo which links to family structure. In this study, I look at who is present in the photo to see if men prefer posting photos of themselves with other people or alone.

A thorough google search into top male instagram influencer accounts offered many repeating names. From this list I identified 10 key influencers with high follow counts to be included in this study. Following research criteria from Siibak (2010) in her study on constructing masculinity on a social networking site, I analyzed the last 5 photos from each influencer and examined each photo under this set criteria. The categories include: participation, activities, behaviour, social distance, body display and location. Siibak based these categories off research from Goffman (1976) which was then followed by Umiker-Sebeok (1981) and Kang (1997). The original categories were used to study magazine advertisements but "the previous studies have shown that they function well on analysis of photographs on SNS [social networking sites]" (Siibak, 2010 p. 410-411). As Siibak stated succinctly in her study, photographs that people post of themselves on their social media can be counted as "advertising the self."

\section{Participation}

The participation category looks at who is also seen in the photo. It considers if they are of the opposite sex, a big or small group, if this group is of mixed genders or not or if they are posing with inanimate objects. The purpose of this category is to see if there is a significant number of photos of men posing single compared with others.

\section{Activities}

The activities category is to see if the majority of men pose for photos with or without being purposefully engaged in an activity. Examples of activities could be various sports or romantic moments such as kissing or embracing friends/partners. Activities could also be everyday doings such as talking on the phone, eating or drinking. 


\section{Behavior}

The behavior category takes into account camera angles and expressions that are used to analyze the way the person looks at the camera. There are four angles as the basis for analysis. Starting, there is the demand/affiliation angle where there is no power difference between the model and the viewer. The image is at eye level and the model is looking directly at the camera warmly. The second angle is demand/seduction in which the model looks up at the viewer with their head tilted and gives a seductive smile or pout meaning that the viewer is asked to desire the person in the photo. After, there is the demand/submission angle in which the model looks down at the viewer as if they are in a position of authority. Finally, there is the offer/ideal angle where the models 'offer' themselves to the viewers as if they are objects in a display case.

\section{Social Distance}

Social distance takes into account the distance from where the photo was taken. This is to analyze if men place more importance on their face or body. Like behaviour, there are many distances to consider. First, there is the intimate distance which marks the closest of human relationships in which we only see the face of the human in the photo. There is also the close personal distance which symbolizes the close intimate relationships but at a distance. In these photos one could hold or grasp the other person and therefore head and shoulders are visible. The far personal distance shows subjects of personal interest and they can be seen from the waist up.

The close social distance is the distance from which 'impersonal business occurs' and people's full bodies can be seen. The far social distance has a more impersonal feeling than in the closer version. The whole figure can be seen with space around it. Finally, there is the public distance which is the distance between people who 'are and are to remain strangers.' In this angle the whole body can be seen and about 4-5 other people.

\section{Body Display}

The body display category simply takes into account what the model is wearing. It asks if they are wearing revealing or hardly any clothes. If their shirts are buttoned all the way up or if we can see their torso. It asks if they are wearing underwear, swimsuits, shorts, only a towel or if they are simply nude. This is analyzing whether or not men emphasize their body in a sexual way.

\section{Location}

Finally, the location category examines where the picture is taken. It asks if men are posing in masculine environments.

\section{Analysis}

This section includes ten photos, (one from each influencer that I examined) that capture the essence of what was discovered. The entire sample taken for this study consisted of fifty photos, five from each influencer. Notes were taken on each photo according to the set criteria listed and described above. After completing the analysis, I located one photo from each influencer that exemplified the ideas that were represented in the image. In other words, the photos presented here provide the most precise insight into the key themes that were present in the analysis. 


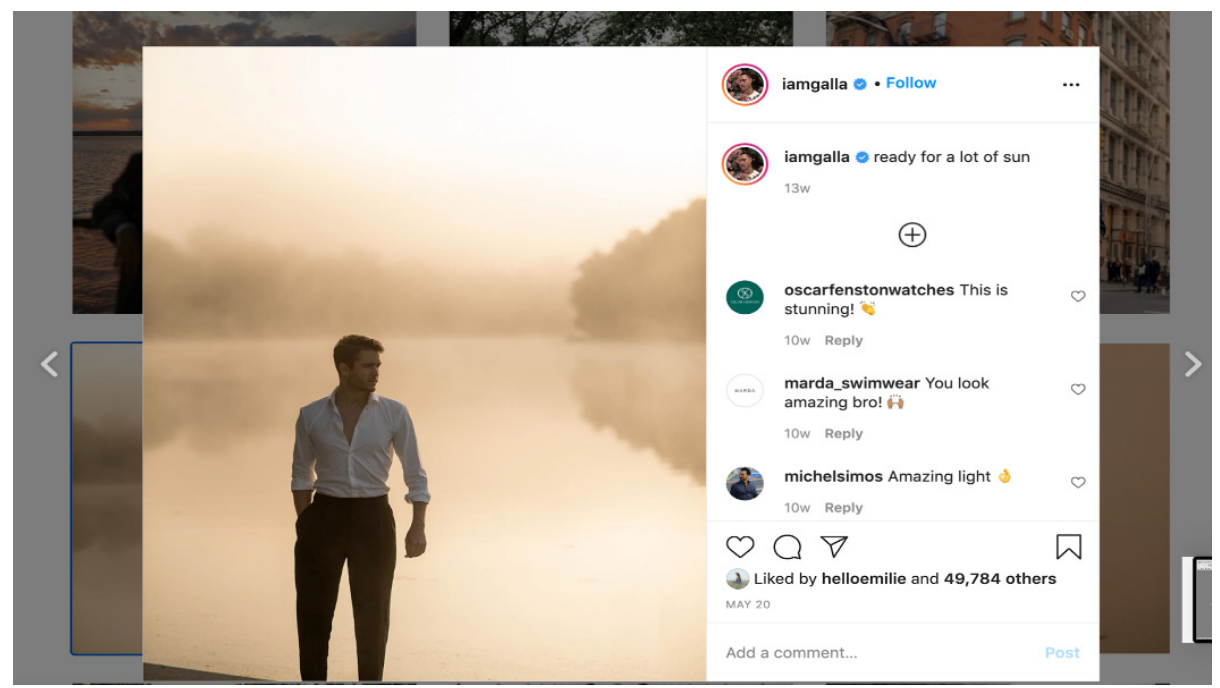

Figure 1. Image of Adam Gallegher.

In Figure 1, from Adam Gallegher's public instagram, I found that he enjoyed posing alone thereby placing more importance on himself than others. In this particular photo he is not seen doing any activities rather than simply posing in front of what appears to be a lake. The location of the lake shore combined with the unbuttoned shirt conveys a romantic atmosphere and makes him look more appealing to the opposite sex. Taken from a far social distance, meaning the whole body can be seen, places more emphasis on his body in relation to the surroundings as one can see his face is also turned away. The behaviour in this photo was classified under offer meaning that he is "offering" himself up to the viewer's attention, he has no agenda in this image. His offer is amplified by his head turning signifying he is just offering himself to the viewers pleasure and the environment.

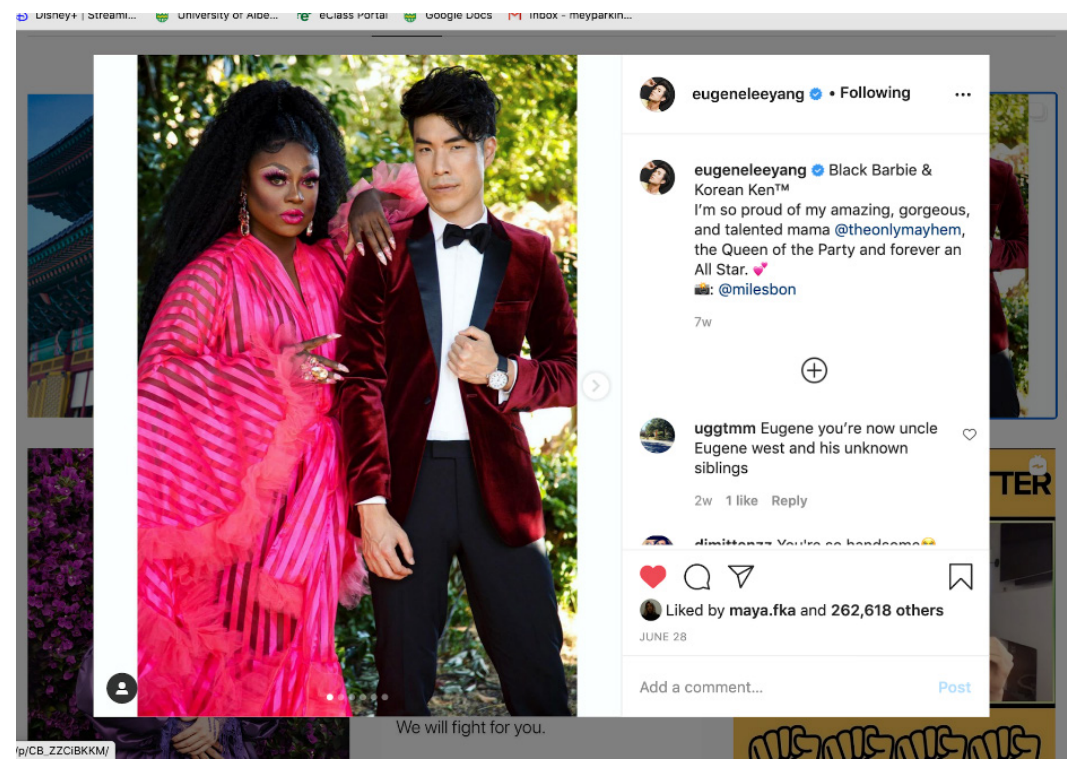

Figure 2. Photo of Eugene Lee Yang

The sample I took from Eugene's page offered a variety of photos to analyze, however, Figure 2 resonated most with my overall findings. Here, Eugene is posing with his drag mother Mayhem Miller. The caption shows Eugene offering his mom lots of love and support. This is different from Figure 1 as the caption is not focused on himself. Again, Eugene is not engaging in any activity but rather offering himself to the viewer by just posing and complimenting his 
drag mother. Also, as the photo is taken from the far personal distance the whole (or almost whole) body can be seen. This puts more focus on his body rather than just his face. Eugene creates an almost seductive look on his face while staring directly into the camera.

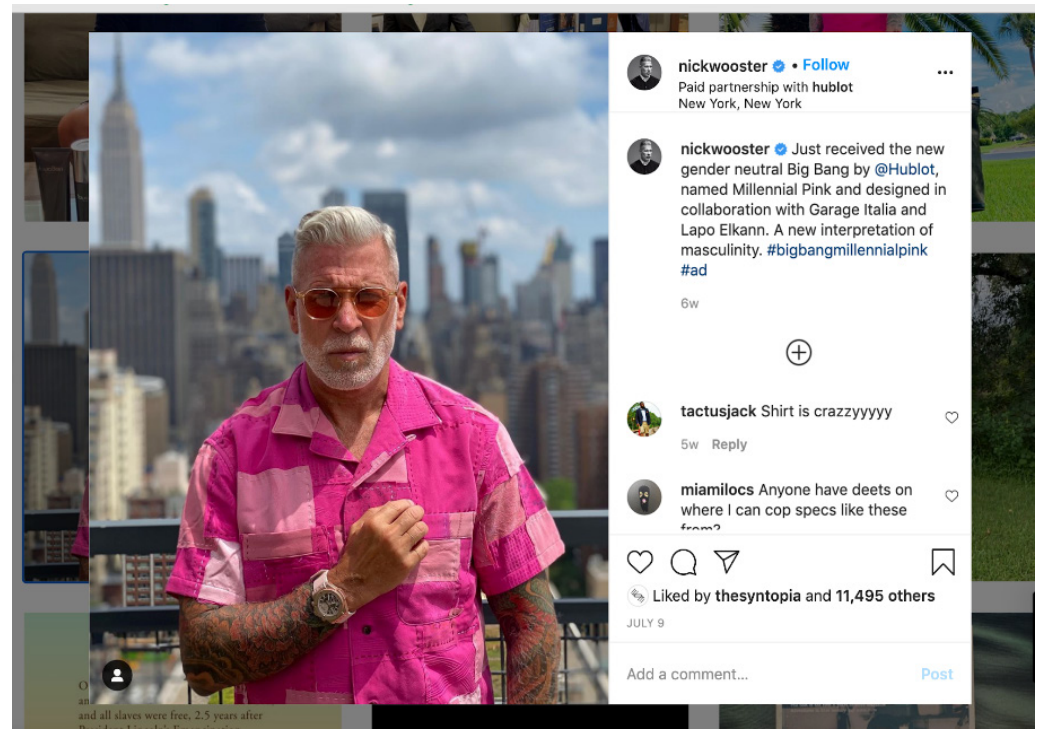

Figure 3. Photo of Nick Wooster

In Figure 3, Nick Wooster poses alone. Again, this solely places emphasis on himself. However, this photo is also an advertisement for his watch so posing alone could simply place importance on the product. Again, he is not doing any specific activity but rather actively posing, offering himself to the product. In this photo, he is looking directly at the camera but with no smile creating a power balance between the model and the viewer. This photo was taken high in the NYC skyline. Altogether, the buttoned shirt, direct gaze into the camera, posing alone and the city setting, creates the image of a powerful man ready to take on whatever comes his way.

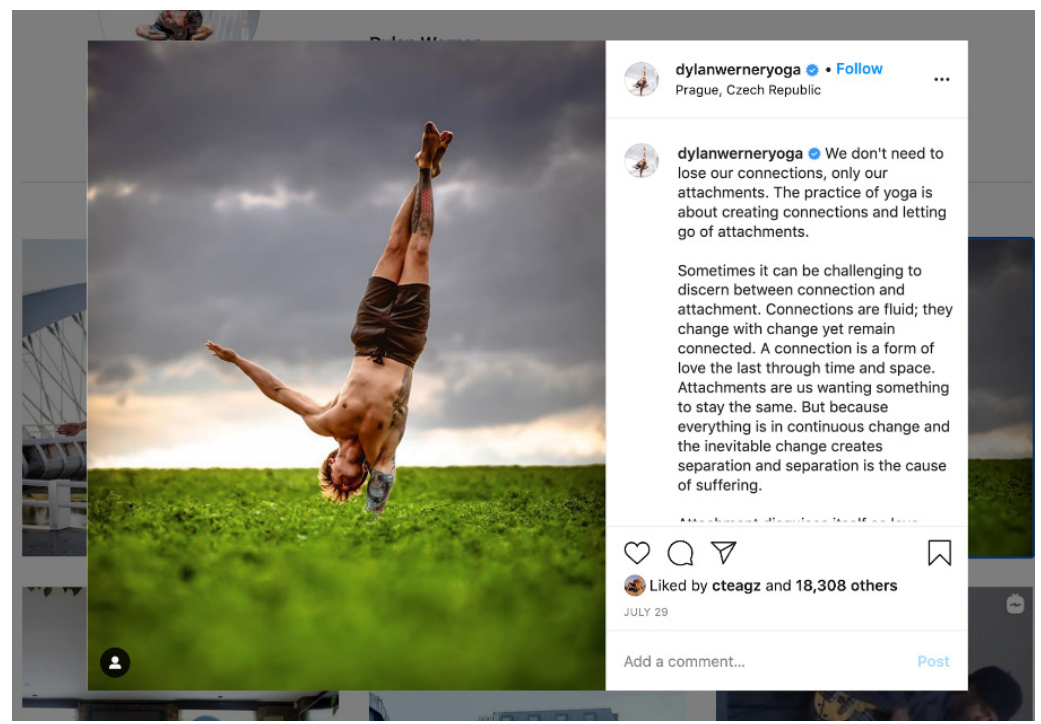

Figure 4. Photo of Dylan Werner

Again, in Figure 4, Dylan poses by himself. This can be a tactic used to pull the full attention of the viewer into oneself and in this case, put focus onto the incredible yoga moves he can do. In this photo Dylan is actively doing yoga which 
presents himself as strong and flexible which can be attractive to the opposite sex. This is a photo that places a lot of emphasis on his figure. One, he is shirtless which shows all of his muscles and strength. Two, the distance the photo is one that purposely shows his whole body and three, his face is turned as to now draw focus away from his body/muscles/strength/skill. This photo was also taken outside which gives the appearance of a typical man, connected to the earth and in charge of himself.

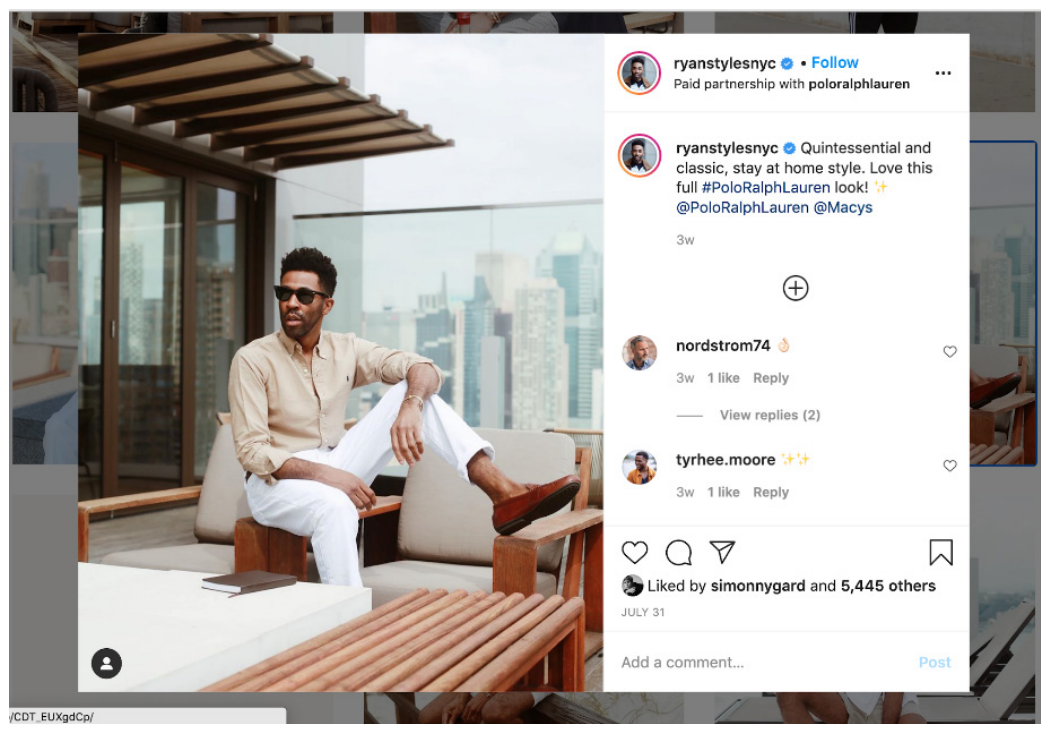

Figure 5. Photo of Ryan Clark

Ryan was another person who's sample I took only depicted himself in the photos (Figure 5). This photo was a paid partnership so the focus was placed on his outfit and can be seen by the fact that he is not looking directly at the camera, thereby offering himself to the viewers pleasure and drawing the attention towards something else. The distance from which the photo was taken also shows the whole body as a way of showing off the outfit. He is outside, on a patio against the NYC skyline portraying a man who is confident and cool.

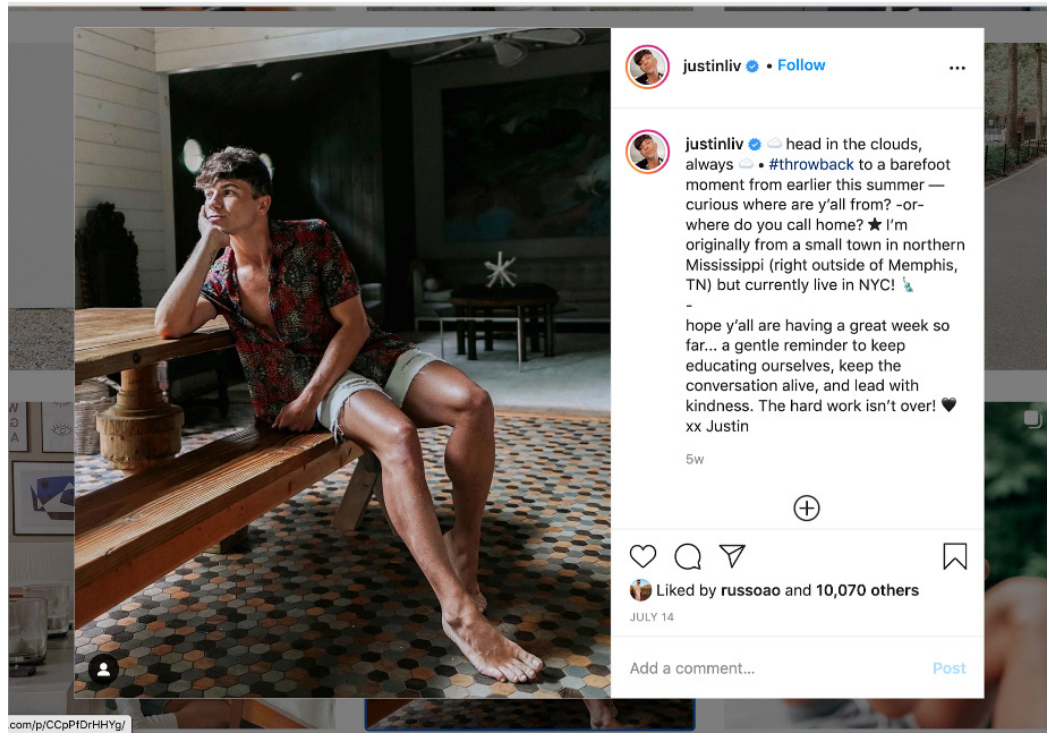

Figure 6. Photo of Justin Livingston 
This photo of Justin Livingston is quite similar to that of Ryan Clark (Figure 6). This photo depicts Justin sitting alone therefore placing all attention on himself. The photo is taken from a close social distance yet showing his entire body again placing attention on his masculine form and not just on his face as his fcae is also turned away from the camera in an offer as he is offering himself to the viewer. The photo appears to be taken on a back patio meaning he is open, warm and not shy, welcoming the viewers into his private spaces (Siibak, 2010, 414).

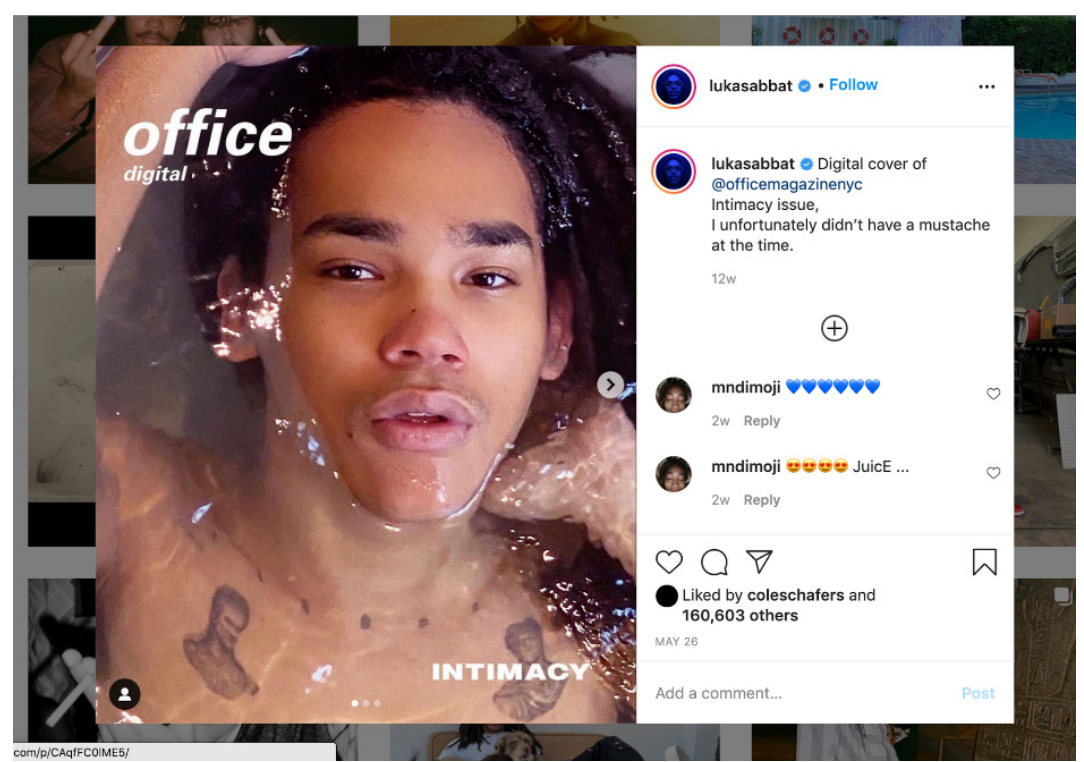

Figure 7. Photo of Luka Sabbat

This photo of Luka Sabbat was taken for office magazine NYC in their intimacy issue (Figure 7). The photo depicts only Luka in a bathtub. Here Luka is shirtless as he is lying in the bathtub with only part of his face not submerged. The photo is taken from an intimate distance only showing his shoulders and face. Luka is looking directly up into the camera with a seductive look on his face. Overall, this photo conveys a lot of sexual/ intimate energy.

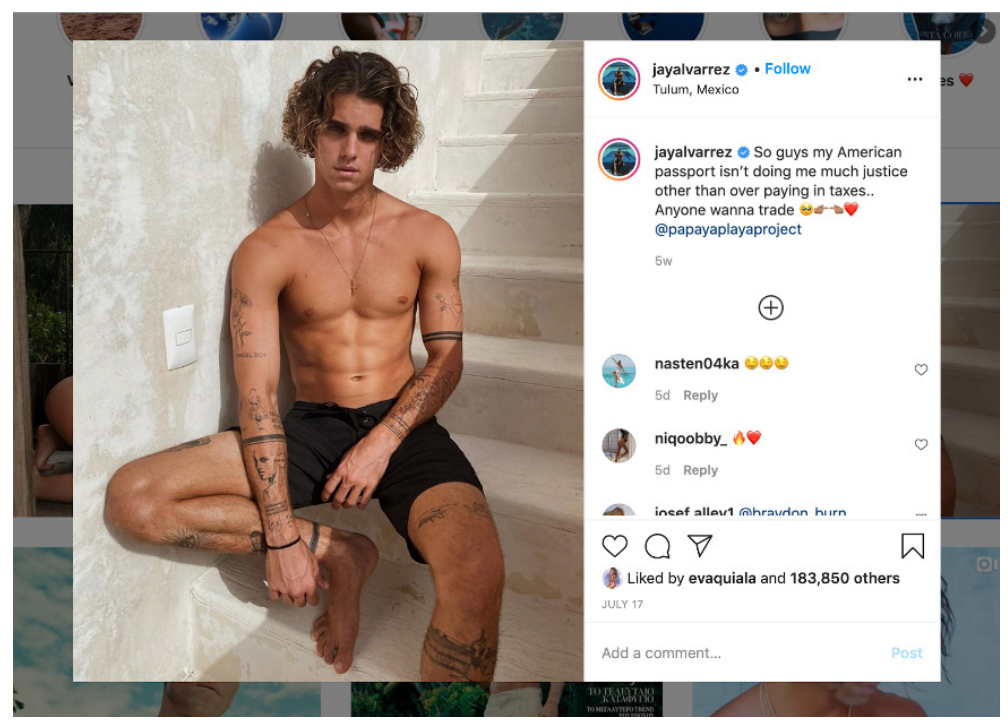

Figure 8. Photo of Jay Alvarrez 
In Figure 8, Jay Alvarrez sits alone placing all importance and attention on himself. Unlike other photos above, Jay looks directly into the camera with a seductive glance which catches viewers attention. However, this photo also draws a lot of attention to the body by the fact that he is shirtless allowing viewers to see his figure and the distance by which the photo was taken allows for the audience to see his body. This photo was taken against a neutral background of white steps. This photo conveys a man who is strong and romantic.

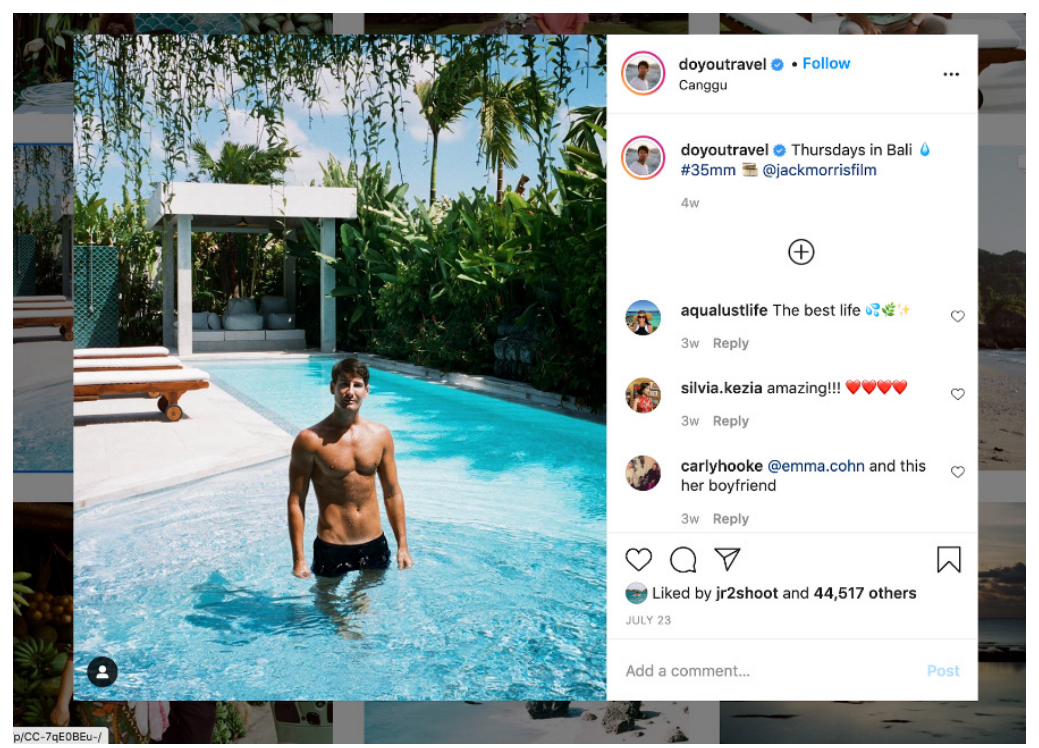

Figure 9. Photo of Jack Morris

In this photo (Figure 9), Jack poses in a swimming pool. Note that he is not actively doing anything in the pool but rather standing and posing offering himself to the viewer and doing this by also standing alone. Here he looks directly into the camera making no power imbalance between himself and his audience. This photo also places lots of attention on his figure as he is shirtless and the distance from which the photo is taken lets the audience view his whole body.

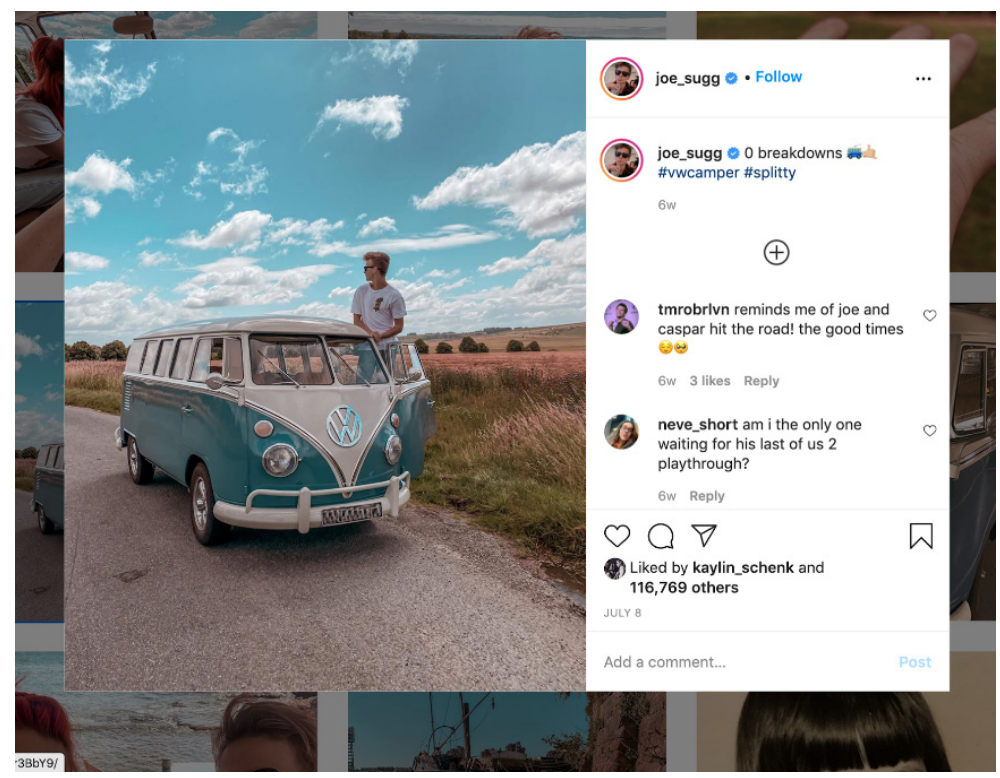

Figure 10. Photo of Joe Sugg 
In Figure 10, Joe Sugg also poses alone standing in his car. He is the only person depicted here but as he is fully clothed and not facing the camera, he is truly offering himself to the environment as another decoration amongst his car and the landscape. Having the photo taken outside depicts a typical man who "...is in charge of his own destiny and has power to change." (Siibak 2010, 413) Also, taking the photo from a far social distance creates room to see not just the model but the surroundings which further illustrates the point that the focus is not entirely on Joe and he is not the main focus of this photo.

\section{Discussion and Conclusion}

This study aimed to see if men, on their own social media platform, portrayed masculinities that are consistent with everyday stereotypes and if these influencers can act as gender socializers. To conduct the analysis, 5 photos that represented the "self" from 10 male influencers were critiqued under a set of criteria. The criteria consisted of participation, activities, behaviour, social distance, location and body display. All of these are factors played into how these influencers portrayed themselves and created their self-image.

The results of this study show that these men are expressing stereotypical displays of masculinity. The samples I chose from each influencer showed great range in self-presentation tactics and range across the criteria chosen to evaluate each photo. Men have found many different ways of expressing both strength and sweetness to appeal to both genders. Certain photos in the study showed very stereotypical masculinity in that they are not smiling and are showing their strength or independence. On the other hand, it is clear that a lot of photos are tools used to show sex appeal as many men posed shirtless or in romantic locations and positions to appeal to their targeted audience.

On multiple occasions, men preferred to pose alone versus with someone else. The majority of these instances and in others where another person may be involved, they chose to not be actively engaged in any activity but rather purposely pose for the photograph. Therefore, men took decorative roles which typically have been reserved for women as featured in Goffman's gender analysis in magazines. By posing and acting as a decoration these men are truly offering themselves to the audience's gaze. Also, greater emphasis has been placed on the male physique. Out of my entire sample, $16 / 50$ photos showed men without wearing a shirt or with their shirts buttoned down. This number excludes photos of the influencers actively showing other skin such as their legs or arms. Further emphasis was placed on the body as most distances used for photos showed the whole body, at least from the waist up. Few photos that were from closer distances also showed skin such as arm muscles and one from an intimate distance showed that the influencer wasn't wearing a shirt. Additionally, in many photos, especially ones where the most importance is placed on the body, the influencers are not facing the camera thereby offering themselves up to viewers interpretations as decorations. There are also plenty of photos in which the influencers were fully clothed but used posing to accentuate their physique. All these images of the male physique play into the hegemonic masculinity views on male sexual power and dominance as a part of their self-presentation.

In Siibak's study (2010) she found that a lot of male self-representation on social media has shifted from hegemonic masculinity “...to a more metrosexual type of thinking." (Siibak 2010, p. 419) Merriam-Websters dictionary defines metrosexual as an urban heterosexual man given to enhancing his personal by fastidious grooming, beauty treatments and fashionable clothes. This discovery also applies to this study as although some of the photos in the sample show typical displays of masculinity, others do portray a high interest in fashion and grooming. This shows that within their masculine presentation there are certain aspects that would be deemed feminine; for example, their awareness of trends (Siibak 2010). Therefore, young men who view these profiles are being shown not the hegemonic masculinity that is imposed by society but rather a type of masculinity that is open and can be more androgynous based on one's own taste.

Future research could include an expanded sample size to facilitate more conclusive insights. One could do this by looking at more photos from each influencer choosing ten or even twenty photos per influencer. Additionally, one could expand the number of influencers that are a part of the study spanning many different areas of expertise such as famous fashion bloggers, youtubers, celebrities and food bloggers -- provided all these people include 
representations of self on their account. Also, one could choose different social media platforms such as TikTok where people can post videos of themselves. This approach to research could focus on representations of masculinity within internet trends such as dances or pranks.

\section{References}

Anderson, E. (2005). Orthodox and Inclusive Masculinity: Competing Masculinities among Heterosexual Men in a Feminized Terrain. Sociological Perspectives, 48(3), 337-355.

Dutro, E. (2002). "Us Boys like to Read Football and Boy Stuff”: Reading Masculinities, Performing Boyhood. Journal of Literacy Research, 34(4), 465-500.

Fracher, J., \& Kimmel, M. S. (1992). Hard issues and soft spots: Counseling men about sexuality. In M. S. Kimmel \& M. A. Messner (Eds.), Men's lives (pp.438-450)

Goffman, E. (1959). The presentation of self in everyday life. New York: Anchor Books.

Kelly, K., \& Donohew, L. (1999). Media and primary socialization theory. Substance use \& misuse, 34(7), 10331045.

MacGregor, Sherilyn and Nicole Seymour (Eds). "Men and Nature: Hegemonic Masculinities and Environmental Change," RCC Perspectives: Transformations in Environment and Society 2017, no. 4.

Philaretou, A. G., \& Allen, K. R. (2001). Reconstructing Masculinity and Sexuality. The Journal of Men's Studies, 9(3), 301-321.

Siibak, A. (2010). Constructing masculinity on a social networking site: The case-study of visual self-presentations of young men on the profile images of SNS Rate. YOUNG, 18(4), 403-425.

Stockard J. (2006) Gender Socialization. In: Handbook of the Sociology of Gender (J.S. Chafetz, ed). Springer, Boston, MA 